\title{
A Model of Listening Engagement (MoLE)
}

\author{
Björn Herrmann ${ }^{1-3^{*}} \&$ Ingrid S. Johnsrude ${ }^{1,4}$
}

${ }^{1}$ Department of Psychology, University of Western Ontario, N6A 3K7, London, ON, Canada

${ }^{2}$ Rotman Research Institute, Baycrest, M6A 2E1, Toronto, ON, Canada

${ }^{3}$ Department of Psychology, University of Toronto, M5S 1A1, Toronto, ON, Canada

${ }^{4}$ School of Communication Sciences \& Disorders, University of Western Ontario, N6A 5B7, London, ON, Canada

*Correspondence concerning this article should be addressed to Björn Herrmann, Rotman Research Institute, Baycrest, 3560 Bathurst St, North York, ON, M6A 2E1, Canada. E-mail: herrmann.b@gmail.com 


\section{Abstract}

26 Hearing impairment in older adulthood puts people at risk of communication difficulties, disengagement from listening, and social withdrawal. Here, we develop a model of listening engagement (MoLE) that provides a conceptual foundation to understand when people engage in listening and why some people disengage. We use the term "listening engagement" to describe the recruitment of executive and other cognitive resources in the service of a valued communication goal. Listening engagement, listening motivation, and listening experiences are closely interconnected: motivation and other factors determine the degree to which resources are recruited during listening, which in turn influences subjective listening experiences such as enjoyment, effort, frustration, and boredom. We anticipate that this model will help researchers assess more accurately whether a person with hearing difficulties is at risk of disengagement and social withdrawal. It is further useful to more comprehensively characterize a person's listening experiences in laboratory settings when rich, engaging stimulus materials, such as spoken stories, are used. We hope this model will allow new questions in applied and basic hearing science and auditory cognitive neuroscience to be asked and answered.

Keywords: Listening engagement, motivation, experience, listening effort, cognitive resources 


\section{Introduction}

Social connectedness and engagement in communication are key factors for healthy aging (WHO, 2002). However, a large minority of people aged over 45 years have some difficulty hearing (Cruickshanks et al., 1998; Feder et al., 2015; Helfer et al., 2017): Clinical hearing loss is typically diagnosed decades after people first experience real-life issues such as trouble understanding speech in the presence of background sound (Pichora-Fuller and Levitt, 2012; Pichora-Fuller et al., 2016). These issues with hearing make communication more difficult (Pichora-Fuller, 2003; Pichora-Fuller et al., 2016), increasing the risk for social isolation (Weinstein and Ventry, 1982; Mick et al., 2014; Shukla et al., in press), which, in turn, contributes to other poor health outcomes (Nicholson, 2009), including an increased risk of cognitive decline (Fratiglioni et al., 2000; Lin and Albert, 2014; Chern and Golub, 2019).

People with hearing impairment may differ in how they cope with it. One person may actively use a hearing aid or adaptive communication strategies, minimizing effects on social engagement, whereas another person may disengage in demanding listening situations, by temporarily zoning out, or electing not to participate in conversation when listening conditions are challenging (Demorest and Erdman, 1987; Hallberg and Carlsson, 1991; Heffernan et al., 2016). The latter person is likely the most at risk for social isolation. Mitigating the psychosocial burden of hearing loss requires a conceptual foundation within which we can understand listening engagement for the purpose of communication. Here, we propose a model of listening engagement that integrates different lines of research to provide such a conceptual foundation.

Hearing impairment is related to a variety of pathologies in the ear, such as hair cell damage (Moore, 2007; Plack, 2014), metabolic changes to the stria vascularis (Gratton and Vázquez, 2003; Gates and Mills, 2005), degeneration of spiral ganglion cells (Bao and Ohlemiller, 2010), and degradation of synaptic connections between inner hair cells and auditory nerve fibers (Kujawa and Liberman, 2009; Liberman and Kujawa, 2017). Beyond the periphery, physiological changes to auditory circuits, such as a loss of inhibition (Caspary et al., 2008; Salvi et al., 2017) and increased hyperresponsiveness to sound (Hughes et al., 2010; Herrmann et al., 2018) are also evident. Hearing impairment is usually associated with diminished sensitivity to sound (degrading the input signal) and diminished acuity. Poorer acuity means that acoustically similar sounds are less discriminable: the signal is harder to segregate from other sounds. As a consequence, hearing loss imposes greater demands on a host of processes involved in perceptual closure, selective attention, and perceptual segregation (Gatehouse and Noble, 2004). For this reason, applied researchers increasingly realize that, in addition to sensory dysfunction, cognitive factors are key to understanding the impact of hearing impairment (Davis and Johnsrude, 2007; Johnsrude and Rodd, 2016; Pichora-Fuller et al., 2016; Peelle, 2018).

Audiometric thresholds and speech intelligibility in noisy situations may be similar for two people, but one may experience substantial effort comprehending speech, whereas the other finds speech comprehension nearly effortless (McGarrigle et al., 2014; Hornsby et al., 2016). Despite substantial enthusiasm in the audiology community for measuring listening effort (Johnsrude and Rodd, 2016; Pichora-Fuller et al., 2016; Peelle, 2018), progress in this area has been limited for at least two reasons. First, "listening effort" is poorly defined. Some use the term to mean a listener's subjective experience 
of difficulty (Johnsrude and Rodd, 2016; Krueger et al., 2017), whereas others use it refer to a mental process or act in which effort is "invested" or "exerted" (McGarrigle et al., 2014; Pichora-Fuller et al., 2016; Peelle, 2018). This conflation of a subjective experience with a mental act has made it difficult to operationalize listening effort. Second, in everyday life, listeners encounter rich speech materials such as gossip, anecdotes, and personally relevant event descriptions in form of narratives or stories. The simple, isolated sentences that are typically used to measure speech intelligibility and listening effort (e.g., "They are buying some bread.") are not very interesting and may not motivate active listening in the same way.

Although listening effort is experienced commonly by people with hearing impairment (PichoraFuller et al., 2016), additional factors likely contribute to why one individual with hearing difficulty disengages and withdraws from demanding listening situations whereas another continues to engage despite challenges. Affective responses (Francis and Oliver, 2018; Schneider et al., 2019; Francis and Love, 2020) - enjoyment in particular (Matthen, 2016) - are likely critical, but questions about what cognitive, experiential, and motivational factors contribute to a person enjoying a conversation or wishing to engage in communication-mediated activities have not been sufficiently explored thus far. Moreover, empirical and conceptual work commonly focuses on the recruitment of resources for or engagement in a listening task, but what happens when a person disengages - including boredom experiences (Elpidorou, 2018a; Westgate and Wilson, 2018) - has been less studied in the hearing sciences.

In this paper, we develop a model of listening engagement (MoLE) that accommodates these factors. We define "listening engagement" as the (automatic or volitional) recruitment of executive and other cognitive resources, when speech comprehension serves a valued communication goal: engagement enables cognitive control and maintains ongoing conscious or explicit involvement in a listening activity such as a conversation. The MoLE captures a wide range of experiences associated with listening (dis)engagement, such as listening effort, enjoyment, frustration, and boredom. The model can be used to predict when individuals who experience hearing difficulty may disengage from listening and may help us understand why. The MoLE further aims to advance hearing science as researchers move towards using richer, more natural stimulus materials, including stories (e.g., Dmochowski et al., 2014; Silbert et al., 2014; Cohen and Parra, 2016; Crosse et al., 2016; Ki et al., 2016; Presacco et al., 2016; Broderick et al., 2018; Fiedler et al., 2019). In what follows, we first review concepts that may illuminate aspects of how individuals engage and what factors may contribute to disengagement. We then introduce the main terms of the MoLE and outline the model. Finally, we discuss future research avenues motivated by this model.

\section{Frameworks Related to Engagement and Disengagement}

\section{Listening effort}

The concept of listening effort has been enthusiastically adopted by applied and basic hearing-science researchers (McGarrigle et al., 2014; Eckert et al., 2016; Johnsrude and Rodd, 2016; Lemke and Besser, 
2016; Pichora-Fuller et al., 2016; Strauss and Francis, 2017; Peelle, 2018), because it can explain variance in behavior that may not be captured by standard hearing assessment tools such as pure-tone audiometry or speech-in-noise intelligibility tests (McGarrigle et al., 2014). Listening effort likely arises as the interaction between a person's hearing status and their cognitive profile (i.e., listener-related factors) and the demands imposed by the specific listening situation (Johnsrude and Rodd, 2016; Lemke and Besser, 2016) such as the nature of the background noise, the spatial configuration of target and maskers, the nature of the target speech material, and other factors (Mattys et al., 2009; Johnsrude and Rodd, 2016). However, establishing a widely accepted definition of the term 'listening effort' has been challenging, despite (or perhaps because of) the intuition most people have about what is meant by it.

Listening effort is a complex psychological construct that may either refer to a mental act or an experience. A person may invest effort (act) in order to understand degraded speech or alternatively finds listening to degraded speech effortful (experience). Effort conceptualized as a mental act involves the recruitment of cognitive/mental resources such as attention and memory (Brehm and Self, 1989; Richter, 2013; McGarrigle et al., 2014; Pichora-Fuller et al., 2016; Francis and Oliver, 2018; Peelle, 2018; van der Wel and van Steenbergen, 2018). Effort has been defined as "the deliberate allocation of mental resources to overcome obstacles in goal pursuit when carrying out a task" (p. 5S, Pichora-Fuller et al., 2016), "the resources or energy actually used by a listener to meet cognitive demands" (p. 205, Peelle, 2018), "the mental exertion required to attend to, and understand, an auditory message" (p. 434, McGarrigle et al., 2014), or as "energy investment" (p. 6, Brehm and Self, 1989; Richter, 2013, 2016). Some authors do not separate the recruitment of cognitive resources from the experience of effort, whereas others use the term explicitly to refer to both (Lemke and Besser, 2016) or distinguish between resource recruitment and the experience of having to commit resources (Francis and Love, 2020).

One issue with defining listening effort as a mental act is that cognitive resources are not monolithic: different challenges are met in different ways. For example, when speech is masked energetically (i.e., by a meaningless noise with components that are sufficiently intense and overlapping in frequency with the target speech to physically obliterate some of it) then the missing information must be inferred from what was perceived. Important cognitive abilities to mitigate this challenge would include inferencing based on context, which requires semantic memory and working memory, particularly for longer utterances (Johnsrude and Rodd, 2016). In contrast, speech-on-speech masking involves relatively little energetic masking - both speech signals are perceptible in the sound mixture. This challenge requires that two meaningful streams of sound are perceptually segregated and distinguished so that one can be selectively attended. Relevant cognitive functions would include cognitive control and distracter suppression (Mattys et al., 2009; Johnsrude and Rodd, 2016).

In the current work, we restrict the term 'listening effort' to refer to a person's experience during listening (cf. Westbrook and Braver, 2015; Johnsrude and Rodd, 2016; Krueger et al., 2017). This experience is the consequence of the recruitment of cognitive and other resources, is assumed to be conscious and explicit, and may be operationalized as subjective ratings after introspection (Larsby et al., 2005; Desjardins and Doherty, 2013; Alhanbali et al., 2017; Krueger et al., 2017) ${ }^{1}$ or assessed using

\footnotetext{
${ }^{1}$ Subjective reports and introspection can be biased (Althubaiti, 2016) and certain populations may underreport experiences (Kamil et al., 2015). Introspection may further be challenged by the limited access to higher level mental processes (Nisbett
} 
qualitative methods. We suggest using the broader term 'listening engagement' to describe the recruitment - explicit and conscious or not - of executive and other cognitive processes in the service of a communication goal. Limiting "listening effort" to experience acknowledges that a person may recruit cognitive resources, while not subjectively experiencing effort, particularly when resource recruitment is relatively modest. Empirical evidence further supports this, showing that subjective and objective (e.g., physiological) measures of listening effort may not always correlate (Miles et al., 2017; Strand et al., 2018; Alhanbali et al., 2019; Lau et al., 2019) and that conscious access to mental processes is limited (Nisbett and Wilson, 1977; Francis and Love, 2020). We propose that listening effort may be viewed as one subjective experience among many during engagement: others include enjoyment and frustration. ${ }^{2}$ As well, when engagement fails, listeners may experience mind wandering and boredom (Westgate and Wilson, 2018). Different experiences (such as effort and enjoyment) may even be experienced simultaneously when listening conditions are challenging.

\section{Motivation and effort}

Motivation refers to "the forces that drive and direct behavior" (p. 697, Dweck, 2017). A person's motivation to understand what is spoken - the importance to them of comprehending what is said - is prerequisite to the recruitment of executive and other cognitive resources (Mitchell, 1982; Picou and Ricketts, 2014; Baumeister, 2016; Pichora-Fuller et al., 2016; Peelle, 2018). Motivation intensity theory (Brehm and Self, 1989; Gendolla and Richter, 2013; Richter, 2013) assumes such a goal, and states that the degree to which executive and other cognitive resources are recruited is determined by the interaction between the experienced (or anticipated) difficulty, one's own abilities, and the importance of being successful. As long as the goal (e.g., speech comprehension) is somewhat realizable, and as long as the necessary effort is justified by the potential outcome (e.g., the listener wishes to comprehend), resource recruitment will increase with increasing listening challenges, such as increasing level of background noise in a crowded restaurant.

\section{Narrative engagement}

Diminished auditory sensitivity and acuity (Moore, 2007; Plack, 2014), hyperacusis (Baguley, 2003; Tyler et al., 2014), and listening effort (Pichora-Fuller et al., 2016) are aversive listening experiences. However, focusing on aversive factors may not be sufficient to predict whether a person disengages from listening or continues despite challenges (Matthen, 2016), or whether a person fitted with a hearing aid will wear it (Solheim et al., 2012; Hickson et al., 2014; Matthen, 2016). Individuals are not only driven to avoid aversive factors, but also seek positive experiences such as enjoyment and interest (Madsen and Moore, 2014; Matthen, 2016; Duchesne et al., 2017; Westgate and Wilson, 2018). It is thus necessary to consider these listening experiences as well as aversive ones.

and Wilson, 1977; Francis and Love, 2020). Nevertheless, we consider the subjective nature of listening experiences - the "feel" - an important factor that contributes to whether a person engages in or disengages from listening.

${ }^{2}$ It is theoretically possible to measure experiences objectively, but there must be a clear link between the experience and the measure. For example, the time a person smiles may be a proxy for how good a person feels. 
The assessment of listening engagement poses challenges to current research approaches. Empirical work often relies on the presentation of brief, isolated sentences that lack a broader context, do not follow a topical narrative, and are not relevant to the listener (e.g., Zekveld et al., 2010; Desjardins and Doherty, 2013; Alhanbali et al., 2017; Krueger et al., 2017). Individuals may listen to such isolated sentences when extrinsically motivated (e.g., by monetary incentives) but may be less motivated to do so intrinsically (for reviews about extrinsic and intrinsic motivation see Ryan and Deci, 2000; Benabou and Triole, 2003). Individuals are more likely to be intrinsically motivated to engage with gossip, anecdotes, and event descriptions in form of narratives and stories that are embedded in a broader context, follow a topical thread, and are meaningful to the person. ${ }^{3}$ Narratives, stories, and other kinds of spoken language are instrumental for everyday life as they shape our understanding of the world and ourselves, convey cultural history, and enable social connectedness (Graesser et al., 2002; Ryan, 2007; Mar and Oatley, 2008; Bamberg, 2010; Dunlop and Walker, 2013).

The study of how individuals engage with narratives and stories is the traditional purview of literature and media studies (e.g., Albrecht and O'Brien, 1993; Oatley, 1999; Green et al., 2004; Busselle and Bilandzic, 2008, 2009; Kuijpers et al., 2014; Bilandzic and Busselle, 2017), and this work provides a helpful starting point to understand the benefits of listening - such as enjoyment - that contribute to maintenance of a listening goal, and hence listening engagement. Narrative engagement frameworks integrate several psychological and folk-psychological constructs (Busselle and Bilandzic, 2009; Kuijpers et al., 2014). These include attentional factors, such as losing awareness, losing a sense of time, and being deeply focused (Kuijpers et al., 2014), or being in a state of "flow" (Csikszentmihalyi, 1990); mental imagery, such as generating images about surroundings, characters, and situations in one's mind (Kuijpers et al., 2014; Scheibe and Barrett, 2017); emotions and empathy, such as feeling with and for characters, and identifying with others (Cohen, 2001); and "transportation", meaning the experience of entering a story world (Green et al., 2004). These experiences are rewarding and so have motivational consequences for listening. Given the increasing number of cognitive-neuroscience studies that utilize audio books and spoken narratives (Lalor and Foxe, 2010; Ki et al., 2016; Keitel et al., 2017; Puvvada and Simon, 2017; Broderick et al., 2018; Fiedler et al., 2019), this area is of substantial potential relevance.

\section{Boredom and cognitive engagement}

Research on boredom and cognitive engagement is directly concerned with understanding when, and why, a person disengages from an activity; this research has not received much attention in the hearing science community. Boredom involves feeling restless, unchallenged, and that the situation serves no purpose (Tilburg and Igou, 2012), and that engaging in a satisfying way is not possible (Eastwood et al., 2012; Westgate and Wilson, 2018). Boredom incorporates two constructs: boredom proneness and boredom state (Farmer and Sundberg, 1986; Fahlman et al., 2013; Chin et al., 2017). Boredom proneness refers to a disposition or trait of a person (Farmer and Sundberg, 1986; Chin et al., 2017) and is associated with frequent experiences of boredom (Elpidorou, 2014). Boredom state, in contrast, refers to boredom

\footnotetext{
${ }^{3}$ Extrinsic and intrinsic motivation likely interact synergistically (Amabile, 1993).
} 
experienced in a specific situation (Fahlman et al., 2013; Chan et al., 2018; Elpidorou, 2018b, a). Here, we focus on boredom state.

Several factors have been proposed to contribute to boredom (reviewed in Westgate and Wilson, 2018). In brief, boredom may result from (a) inadequate environmental inputs such as understimulation, non-optimal arousal, and constrained choices (e.g., repetitive or vigilance tasks; Westgate and Wilson, 2018); (b) a failure of a person to maintain attention on an activity (Eastwood et al., 2012); and (c) a lack of meaning (Chan et al., 2018). The Meaning and Attentional Components Model of Boredom integrates these different factors (Westgate and Wilson, 2018) and posits that a person may not engage in an activity if it bears low meaning to the person and is incongruent with the person's goals. This mirrors the critical role of success importance in Motivation Intensity Theory (Brehm and Self, 1989; Gendolla and Richter, 2013; Richter, 2013). The Meaning and Attentional Components Model of Boredom proposes that the right level of stimulation is required for a person to engage in an activity, and that the degree to which a person recruits resources for the activity determines their experience of enjoyment and interest (Westgate and Wilson, 2018). Hence, a person may not engage in an activity if situational demands exceed an individual's resources (overstimulation) or if very few resources are required to cope with the situational demands (understimulation) (Westgate and Wilson, 2018).

\section{A Model of Listening Engagement (MoLE)}

In this section, we introduce the Model of Listening Engagement (MoLE) that aims to provide a conceptual basis to understand how individuals engage in listening and communication and what they experience during listening. We start with a brief description of the relevant terms of the MoLE (see Table 1) that also reflect variables in the mathematical implementation of the MoLE (see Appendix).

\begin{tabular}{ll} 
Terms & Description \\
\hline Resource & A neurophysiological competence that supports task engagement. \\
Resource limit & The maximum amount of a resource that can be utilized at a given time. \\
Required amount & The amount of a resource that is required to meet the situational demands. \\
Available amount & $\begin{array}{l}\text { The amount of a resource that is available (or is anticipated to be available) after } \\
\text { the required amount of the resource is recruited. }\end{array}$ \\
Recruited amount & The amount of a resource that is actually utilized. \\
Motivation & The forces that drive and direct the recruitment of resources. \\
Engagement & The recruitment of resources to participate in an activity. \\
Experience & Subjective, qualitative state depending on all other variables
\end{tabular}

Table 1: Terms and descriptions of the Model of Listening Engagement (MoLE)

The MoLE assumes that a person is equipped with a variety of cognitive resources that enable the person to adapt to their listening environment. Individual resources may or may not interact. In a given listening situation, a required resource is recruited (recruited amount) up to a theoretic maximum (resource limit). The required amount of a resource refers to the amount that is (or would be) needed in order to comprehend what is being heard. The available amount of a resource is the amount that is left 
over and could be used for other, unrelated tasks after situational demands are accounted for. A person's motivation refers to the forces that drive and direct the recruitment of resources, for example, by the success importance and personal relevance of speech comprehension in a given situation. If a person's motivation is low, resources may not be recruited, even if the resource limit is higher than the required amount. We define engagement as the recruitment of resources during listening. A person will only maintain engaged in the face of listening challenges when the person is motivated and sufficient resources are available. Experiences such as enjoyment, boredom, effort, and frustration are determined by the interaction between the available amount of a resource, engagement, and motivation.

\section{Resource, resource limit, required resource, and available resource}

The MoLE shares the common assumption with other information processing and cognitive control models that individuals are equipped with cognitive resources (Kahneman, 1973; Norman and Bobrow, 1975; Hockey, 1997; Lavie, 2005; Lavie et al., 2014; Lemke and Besser, 2016; Pichora-Fuller et al., 2016; Wingfield, 2016). We assume the existence of multiple, differentiable, cognitive resources (cf. Navon and Gopher, 1979; Wickens, 2002, 2008), since (partially) different neural circuits are recruited for different cognitive challenges, although some neural circuits may be common to several cognitive processes (Kanwisher and Wojciulik, 2000; Scott and Johnsrude, 2003; Eckert et al., 2016; Zanto and Gazzaley, 2017; Peelle, 2018). We assume that these cognitive resources are common to most people, and that the endowment differs across resources and varies across people: we each have a unique cognitive profile. We are, however, agnostic about what constitutes a cognitive 'resource', since the taxonomy of mental functions is still not clear (Poldrack and Yarkoni, 2016): we do not assume that these are necessarily the functional constructs to which psychologists give names (such as working memory, attention, cognitive control, goal maintenance), since this may not be how nature carves up cognition 'at its joints' (cf. Summerfield and Egner, 2009; Gazzaley and Nobre, 2010; for a discussion about resource concepts see Sanders, 1997). Moreover, how cognitive processing emerges from neural anatomy and function is not well understood: current perspectives include the activation of specific brain regions or networks of regions (Eckert et al., 2016; Peelle, 2018), synchronized oscillations that dynamically form neural ensembles (Fries, 2005; Miller and Buschman, 2015), and the depletion of astrocytic glycogen to fuel sustained neuronal activity (Gailliot, 2008; Christie and Schrater, 2015), among others. Functional substrates and implementations may even differ for different cognitive resources.

Cognitive processing must operate within biological constraints (Christie and Schrater, 2015; Miller and Buschman, 2015), and the MoLE thus shares the view with other models that the maximum amount of a resource that a person can utilize (the resource limit) is finite (Kahneman, 1973; Norman and Bobrow, 1975; Wickens, 2002; Lavie, 2005; Lavie et al., 2014; Lemke and Besser, 2016; PichoraFuller et al., 2016; Wingfield, 2016; for a detailed discussion of resource limits see Shenhav et al., 2017; see also Inzlicht et al., 2014). Greater resource limits increase the probability that an individual can listen and behave effectively across a variety of situations. How resource limits are implemented neurally is not well understood (suggestions involve synchronized oscillation; Miller and Buschman, 2015; or storage capacity of astrocytic glycogen (Gailliot, 2008; Christie and Schrater, 2015). Whereas resource limits are often considered to be relatively stable over an extended period - from one situation to the 
next (Lemke and Besser, 2016) - there may be some degree of elasticity in resource limits under high task demands (Kahneman, 1973). Resource limits may also be reduced by fatigue and other temporary states (Wright, 2014; Richter et al., 2016). Larger changes in resource limits may occur over longer periods in healthy individuals, for example, as individuals mature and then senesce (Glisky, 2007; Park and Reuter-Lorenz, 2009; Lindenberger, 2014; Phillips, 2016), or more suddenly in individuals with brain injury or disorders (Reitan and Wolfson, 2000, 2004).

A Requirement, limit, and recruitment of resources

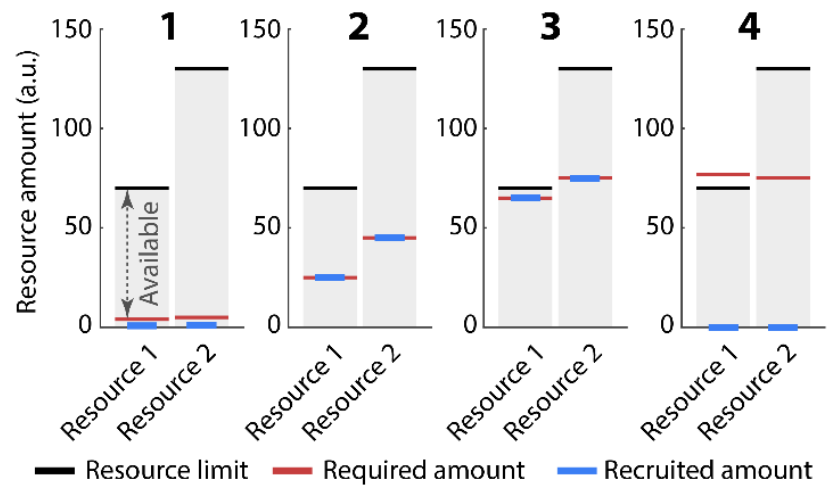

\section{B Engagement}

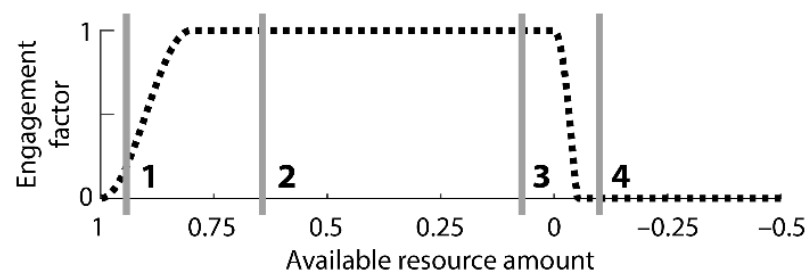

Figure 1: Predictions of the Model of Listening Engagement (MoLE). A: Resource limits, required amounts, and recruited amounts for four sample cases: (1) Required and recruited resource amounts are negligible; speech comprehension is easy. (2) Required and recruited resource amounts are nonzero, but well below resource limits; speech comprehension is not perceived as effortful. (3) Required and recruited resource amounts approach resource limits; speech comprehension is perceived as effortful. (4) Required resource amounts exceed the resource limit and are not recruited; the listener does not engage. Note that, for simplicity, resources are in arbitrary units. Units could in principle differ for different resources. B: Relation between available resource amount and engagement. The available resource amount reflects (one minus) the proportion of the required amount relative to the resource limit. Engagement is the factor that determines the extent (i.e., proportion) to which the required resources in panel A are actually recruited. In cases 2 and 3 , a person recruits resources and is engaged (engagement factor of one). In case 4, a person does not recruit the required resource amounts and is disengaged (engagement factor of zero). Even when speech comprehension is easy, a person may also disengage; for example, when listening to a long, tedious monologue (case 1; engagement factor approaching zero).

In contrast to resource limits, which are relatively fixed for a given individual, the required amount of a resource reflects the degree to which the demands of a situation - that is, external factors draw on or are anticipated to draw on a resource (Gendolla, 2000; Gendolla and Krüsken, 2001; Richter et al., 2006; Mattys et al., 2012; Johnsrude and Rodd, 2016; Richter et al., 2016). Different situations may differ in their demands (Mattys et al., 2012; Johnsrude and Rodd, 2016): Listening to a friend talk about their kids in a quiet restaurant requires little resource recruitment from a healthy, normal-hearing person to comprehend (Figure 1A, case 2). Listening to the friend while background music is played in 
the restaurant and other people talk loudly requires the recruitment of more resources to comprehend (Figure 1A, case 3). If the dinner companion in a noisy restaurant is someone who the listener has only just met and who speaks very fast and with a strong accent, the resources required to comprehend may exceed the listener's resource limits, and the listener may zone out and disengage (Figure 1A, case 4); particularly if the listener is in a group of people, where active participation is not required as much. A listener may also disengage from listening if resource recruitment is relatively modest; for example, when a friend slowly tells a long, tedious story about a person the listener does not know (Figure 1A, case 1). Since listening situations are dynamic, the required amount of resources also varies continuously and is thus also dynamic.

The available amount of a resource is the amount that is not required by the listening situation, and could be used for other, unrelated, tasks. We operationalize the available amount of a resource as the proportion of the resource limit that is not required (i.e., one minus the proportion of the required amount relative to the resource limit; see Appendix). The available amount is calculated for each resource separately. However, a person may not have independent access to different resources during listening in everyday life (Nisbett and Wilson, 1977). We therefore calculate a unique available resource amount as the minimum available resource amount across different resources (see Appendix). We assume that the resource for which the least amount is available - is most influential for a person's subjective experience. The available resource amount is positive when the required amount is within the resource limits and negative when the required amount exceeds the resource limits (Figure 1B).

\section{Engagement, motivation, and recruited resource amounts}

Engagement regulates whether, and to what extent, resources are recruited for an activity. In the MoLE, we operationalize this as shown in Figure 1B (for details see Appendix), where the amount of available resources determines the degree of engagement, that is, the engagement factor. The engagement factor is bounded by zero and one. Zero indexes the absence of engagement (i.e., disengagement), where no resources are recruited for the activity. One indexes maximal engagement, where the recruited amount matches the required amount (Figure 1B). In other words, the engagement factor determines the proportion of the required resources that are actually recruited (cf. Brehm and Self, 1989; Richter et al., 2016), but we posit that, in real life, the engagement factor will be either zero or one, making engagement essentially binary.

The recruitment of resources is energetically and metabolically expensive (Westbrook and Braver, 2015; Shenhav et al., 2017). A person will recruit resources to comprehend speech only if comprehension is a valued outcome (Brehm and Self, 1989; Richter, 2013). Motivation can be defined as "the forces that drive and direct behavior" (p. 697, Dweck, 2017), speaking to the willingness of a person to recruit resources for and engage in an activity (Mitchell, 1982; Baumeister, 2016). Motivation depends on the value of the anticipated outcome. Motivation is higher if the activity is meaningful and/or personally relevant (Brehm and Self, 1989; Heine et al., 2006; Gendolla and Richter, 2013; Richter, 2013). As such, motivation is considered fundamental to all aspects of human cognition, emotion, and behavior (Baumeister, 2016; Dweck, 2017). 
353 Pichora-Fuller, 2016; Peelle, 2018).

\section{3}

5

\section{Interaction between resources}

In the MoLE, motivation drives the relation between the available resources amount and the engagement factor, and hence engagement (Figure 2, cf. Pichora-Fuller et al., 2016; Peelle, 2018). When motivation is high, a person will recruit one or several resources and engage even when the activity requires recruitment of resources up to the limit (engagement factor of one; Figure 2). When motivation is low, a person may not engage in listening even if resources are or would be available (engagement factor of zero; Figure 2). The relation between motivation and resource recruitment (engagement) is consistent with Motivation Intensity Theory (Brehm and Self, 1989; Richter, 2013); models of cognitive control (Westbrook and Braver, 2015); and concepts of listening effort (Picou and Ricketts, 2014;

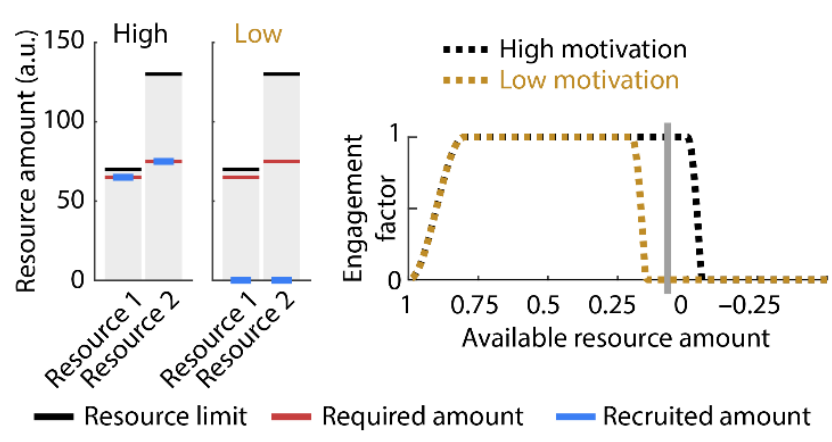

Figure 2: Motivation influences engagement. A person may engage or disengage under similar situational demands (i.e., when the required amount of resources is similar) depending on the person's motivation. The grey vertical line in the right-hand plot indexes the available resource amount for the sample cases on the left (same as case 3 in Figure 1). Under high motivation, a person engages and recruits resources for the activity (engagement factor of one). Under low motivation, a person does not engage and does not recruit resources for the activity even if resource amounts would be available (engagement factor of zero). in time reflects the integration of two factors. One is the quality of the experience the listener is currently below). The other is the likelihood of successful comprehension; whether the listener's resources and the listening conditions enable some level of intelligibility. Only if comprehension is possible and motivation is sufficiently high will the listener engage and recruit resources. Motivation (and engagement) will shift dynamically as a function of these two factors, which are changing over time.

Resource constructs such as working memory or attention are often studied in isolation (in theory) and we have thus far assumed that they are independent (but see Summerfield and Egner, 2009; Gazzaley and Nobre, 2010 for exceptions). But of course, the human brain has evolved to work as an integrated whole, with conceptually different systems naturally interacting (Wickens, 2002, 2008); and this is most likely the case in the real-world listening situations that concern us here. Structurally similar, concurrent tasks may interfere with each other by requiring amounts of the same resource (Wickens, 2002, 2008). Speech comprehension under situational demands requiring different resources may benefit from interaction between resources. Resources may compensate one for another under challenging listening 
conditions such that additional amounts may be recruited for one resource in order to increase the limit of another resource (Figure 3; other strategies may rely on filling in missing information based on predictions and redundancy in acoustic streams; Shinn-Cunningham, 2008). This may be accomplished through increased neural activity in common networks - such as cingulo-opercular and fronto-parietal systems (Eckert et al., 2016; Peelle, 2018). We assume that such compensation may be possible only temporarily, only when the resources are not entirely independent, and only under challenging conditions.

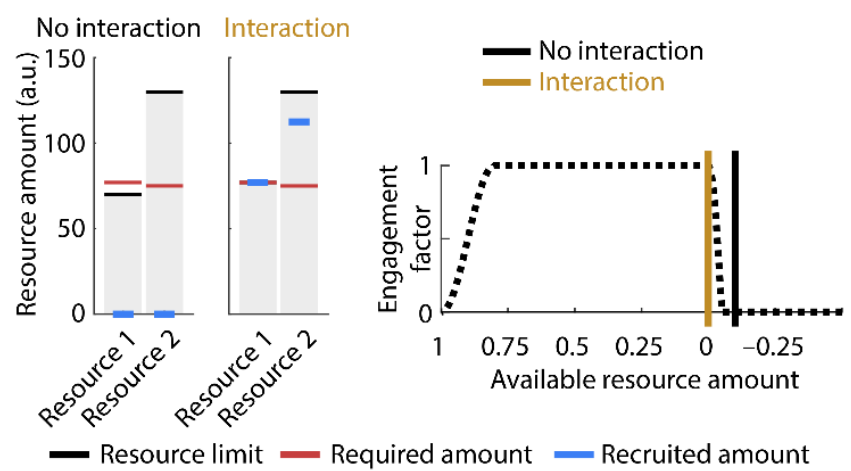

Figure 3: Interaction between resources. Lefthand pair of bars: no interaction. The two bars are identical to case 4 in Figure 1. The required amount (red) of resource 1 exceeds the person's resource limit (black). The person would not engage (vertical black bar in graph on right of the figure) nor recruit resources (blue). Right-hand pair of bars: A compensatory interaction between resources may help extend resource limits in the same listening situation. Recruiting more of resource 2 may temporarily increase the limit of resource 1 (to match the required resource amount), enabling the listener to engage (vertical gold bar in graph at right of the figure) and recruit sufficient resources (blue).

\section{Experience}

In previous sections, we have described the factors that influence whether a person engages or disengages in a listening situation: A person with sufficient available resources will engage and recruit resources if anticipated comprehension is valued. This engagement or disengagement is potentially accompanied by a variety of subjective experiences.

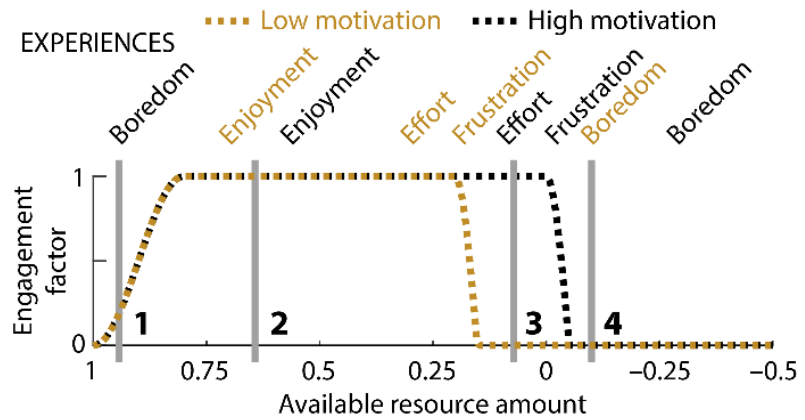

Figure 4: Samples of experiences in the MoLE. The grey vertical lines mark the available resource amounts for cases 1-4 in Figure 1. A listener highly motivated to comprehend speech may engage and experience enjoyment (case 2) or effort and possibly frustration (case 3), but may disengage and experience boredom in cases 1 and 4. A less motivated listener may disengage and be bored in case 3 , although the required resources do not exceed the listener's resource limits.

In the MoLE, listening experiences depend on motivation and available resource amounts (cf. Westgate and Wilson, 2018; Figure 4). Listening effort may be experienced when recruited amounts approach resource limits (Johnsrude and Rodd, 2016; see also Brehm and Self, 1989; Pichora-Fuller et al., 2016; Peelle, 2018). Frustration may be experienced when motivation is high, and required resource 
amounts just exceed resource limits and recruited amounts approach or are at resource limits (GarciaLeon et al., 2003; Francis and Oliver, 2018). Boredom may be experienced when a person is disengaged from listening either because required resources exceed resource limits (overstimulation) or because recruited resources are very low (understimulation) (Westgate and Wilson, 2018) either because they are not required or because motivation is low. Although often not a focus of hearing-related research, enjoyment may be experienced when an individual is motivated to listen and is therefore engaged, even if resource recruitment is considerable (cf. Matthen, 2016).

Indeed, a listener's motivation has a strong effect on listening experiences (Figure 4). For example, a highly motivated listener may engage and experience effort and possibly enjoyment or frustration (depending on success) in a highly demanding listening situation, such as a crowded restaurant, but may not engage, and so experience boredom, in the same situation if less motivated (Figure 4, case 3).

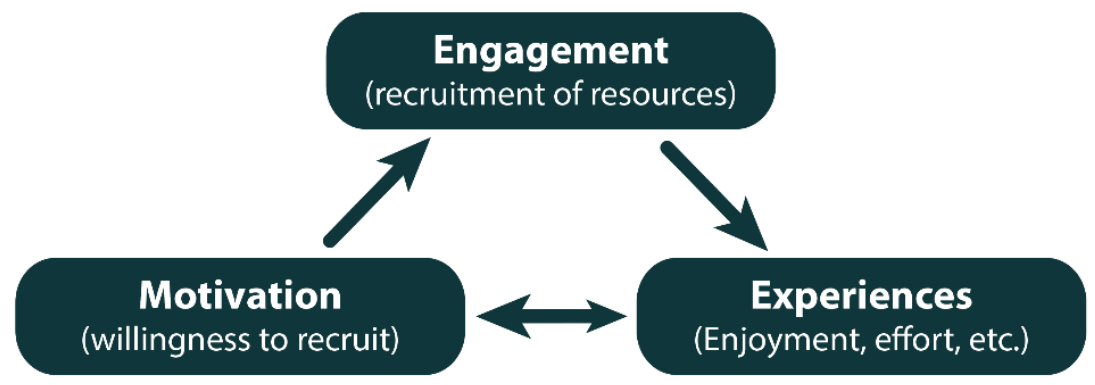

Figure 5: Relation between engagement, motivation, and experiences. A person's motivation and the relation between required resources and resource limits (i.e., available resource amounts) determine engagement. These characteristics determine success and listening experiences, which also influences motivation.

398

399

400

401

402

403

404

405

406

407

408

409

410

We propose that a person's experiences, motivation, and engagement in a listening situation are inter-connected (Figure 5; cf. Hockey, 1997; Matthen, 2016; Pichora-Fuller et al., 2016; Richter et al., 2016; Peelle, 2018; Schneider et al., 2019). Experiences and the associated affect may influence a listener's motivation to engage (Wright et al., 2003; Schneider et al., 2019; Francis and Love, 2020). The degree of engagement, in turn, affects a person's experiences. For example, a person experiencing enjoyment may be motivated to continue to engage, which, in turn, may foster enjoyment (Green et al., 2004). A person experiencing effort or frustration in a challenging listening situation may lose motivation and disengage. The experience of boredom may motivate a person to engage and listen (in order to avoid boredom) or to find another, more meaningful activity (Elpidorou, 2018b, a; Westgate and Wilson, 2018). We further suggest that motivation can directly affect the quality of a listening experience (Figure 5), for example, by setting an affective tone when a listener is highly motivated (positive influence on experience) or very unmotivated (negative influence on experience). The interdependence of engagement, motivation, and experience makes listening dynamic. 
411

412

413

414

415

416

417

418

419

420

421

422

423

424

425

426

427

428

429

430

431

432

433

434

435

436

437

438

439

440

441

442

443

444

445

446

447

448

\section{A broader view of experience}

"Experience" has been referred to as "an elusive concept that resists specification" (p. 44, Wright et al., 2003). It can be thought of as reflecting the integration of affective, cognitive, and behavioral sources of information (Nabi and Krcmar, 2004). As such, "experience" has been described as a holistic sensemaking process (Wright et al., 2003) that combines contextual elements and their relations (e.g., experiences during a conversation in a restaurant may be affected by the table size, distance to other tables, and chair comfort), sensual elements (such as the 'feel' of a situation; e.g., welcoming or hostile communication partners), emotional elements (such as anger, joy, satisfaction, fulfillment), and spatiotemporal elements (such as losing a sense of time during engagement or perceiving space as confined during frustration; Wright et al., 2003). Hence, the quality of a listening experience may vary depending on these factors.

Listening effort is often assessed using rating scales (Larsby et al., 2005; Mackersie and Cones, 2011; Francis et al., 2016; Krueger et al., 2017) or (unidimensional) physiological measures (Zekveld et al., 2010; Strauß et al., 2014; Wöstmann et al., 2015; Holube et al., 2016; Wendt et al., 2016; Dimitrijevic et al., 2017). Yet, listening effort is a rich experience that may yield different qualities depending on a variety of factors (Marinelli, 2017) that may not be fully captured using standardized measures. For example, effort experienced because a listener has to inhibit distracting sounds (e.g., a person behind the listener talking loudly) may differ qualitatively when the listener is highly motivated to comprehend speech compared to effort experienced when listening is a chore, and not a pleasure. Other experiences such as enjoyment can be thought of as being similarly rich and complex (Nabi and Krcmar, 2004).

Experiences may also co-occur and interact. Effort and boredom may co-occur, for example, in situations mirroring vigilance tasks (Thackray et al., 1977; Eastwood et al., 2012). Enjoyment may cooccur with experienced effort (Csikszentmihalyi, 1990). Conversing with and listening to a friend in a crowded restaurant may be somewhat effortful, but the individuals involved may feel fulfilled, stimulated, and joyful (cf. Matthen, 2016). Considering such interrelations and co-occurrences of listening experiences are important for predicting whether a person will disengage from listening or continue to engage despite challenges.

Finally, considering the social circumstances of a demanding listening situation may be crucial for understanding engagement and listening experiences (Caplan and Van Harrison, 1993; PichoraFuller, 2016). A listener with hearing difficulty may "zone out" - that is, temporarily disengage from communication within a social situation (Heffernan et al., 2016; Gfeller et al., 2019) - particularly if the listener is in a group of people, such as in a class room or at a birthday gathering, where active participation is less required - but still enjoy being with their friends and family (which might enhance motivation to engage in listening, even if listening success is low). The overall experience of this listener may be positive, and they would consider participating in such situations in the future. If this listener was anticipating a social situation that was not enjoyable without active participation, they may choose to avoid the situation entirely, or experience frustration if social norms prevent them from disengaging, and other coping strategies fail. 


\section{Listening dynamics}

In a crowed restaurant (for example), motivation, engagement, and experiences of a listener are not static, but vary over time. Background speech may be more intense at some times than at others, conversational topics may be more interesting at some times than at others, the individuals involved in a conversation may have different accents, or a person may become exhausted over time (for factors contributing to listening challenges see Mattys et al., 2012; Johnsrude and Rodd, 2016). Such variations in situational demands (affecting available resources) and person-internal states (affecting motivation) underlie listening dynamics. Consequently, the MoLE indexes engagement only for one moment at a time, but we assume that dynamic changes in engagement are the norm, not an exception. As depicted in Figure 5 , motivation, engagement, and experiences are interconnected, and dynamic changes in any one of these factors will influence the others.

\section{Consequences of the MoLE for empirical research}

The MoLE aims to provide a conceptual foundation enabling us to understand how a person engages in listening and when a person may disengage. The MoLE is a work in progress and, although it is mathematically tractable (see Appendix), it was not specifically designed for quantitative data fitting. In the following, we briefly lay out a few avenues for empirical research that follow from the MoLE.

Previous operationalizations of listening effort have not been entirely consistent: the use of subjective ratings is consistent with effort as an experience (Gatehouse and Noble, 2004; Larsby et al., 2005; Alhanbali et al., 2017; Krueger et al., 2017), similar to the MoLE, whereas physiological measures such as pupillometry are more consistent with listening effort as a mental act (Brehm and Self, 1989; Richter, 2013; Pichora-Fuller et al., 2016; Peelle, 2018). Listening effort and resource recruitment are very different in our view: We consider "effort" as one experience among many other potential listening experiences (Westbrook and Braver, 2015; Johnsrude and Rodd, 2016; Lemke and Besser, 2016; Krueger et al., 2017), and use the term "engagement" to describe the act of investing one or several resources in an activity (cf. Westgate and Wilson, 2018). We posit that engagement is essentially binary although degrees of engagement are theoretically possible. Listening effort may be experienced when recruited resources approach resource limits because of the demands of the listening situation (Johnsrude and Rodd, 2016), but experienced effort does not reflect such demands alone (Westbrook and Braver, 2015); it also depends on motivation and engagement. The experimental protocols commonly employed typically utilize context-free, isolated sentences combined with parametric noise manipulations, and these may not be sufficiently motivating to lead to full engagement or capture the rich and complex nature of listening experiences (Wright et al., 2003; Nabi and Krcmar, 2004).

Listening effort defined as experience further influences how to ask and answer research questions about the underlying mechanisms and behavioral consequences of listening effort. For example, the MoLE predicts that physiological measures such as pupillometry (Zekveld et al., 2010; Wendt et al., 2016; Winn et al., 2018; Zekveld et al., 2018), neural oscillatory activity (e.g., in the alpha frequency band; Strauß et al., 2014; Wöstmann et al., 2015; Dimitrijevic et al., 2017), electrodermal activity (Holube et al., 2016), and others, may tap into resource recruitment, motivation, and/or 
487

engagement, but may not reflect effort experiences to the same extent (cf. Strand et al., 2018; Alhanbali et al., 2019). The MoLE enables us to distinguish among experienced effort, and the factors that may determine it, including motivation and engagement (i.e., resource availability and recruitment).

Besides listening effort, only a few other, mostly aversive experiences, such as frustration (Francis and Oliver, 2018) and fatigue (McGarrigle et al., 2014; Hornsby et al., 2016), have been the focus of research in hearing science. Positive experiences (e.g., enjoyment, satisfaction, fulfillment, interest, etc.) are not commonly studied (but see Matthen, 2016) or are studied only in the context of hearing prothesis use (e.g., Madsen and Moore, 2014; Duchesne et al., 2017). However, positive experiences will likely affect a listener's motivation and, in turn, whether the person engages or disengages (Figure 5; Matthen, 2016). Ignoring the positive experiences individuals seek when engaging in social, communication activities may leave variance in behavioral tests unexplained. Moreover, the materials typically used in speech comprehension studies - that is, simple sentences that have little meaningful context and are not very interesting (e.g., Nilsson et al., 1994; Kilman et al., 2015; Wöstmann et al., 2015; Wendt et al., 2016) - may not motivate listening attentively the way that personally relevant discourse and stories do. The MoLE predicts qualitative differences in neural network activity and how effort is experienced for intrinsically motivating discourses and stories compared to isolated sentences. A research focus on aversive listening experiences will limit progress, particularly if researchers turn increasingly to naturalistic materials, such as stories (Silbert et al., 2014; Ki et al., 2016; Puvvada and Simon, 2017; Daube et al., 2019; Fiedler et al., 2019).

We suggest that engagement, motivation, and experiences are interrelated (Figure 5; cf. PichoraFuller et al., 2016). Any of these relations may be the target of empirical research. The relation between motivation and engagement (or resource recruitment; Brehm and Self, 1989; Gendolla and Richter, 2013; Richter, 2013; Westbrook and Braver, 2015), and the relation between experiences and motivation (Wright et al., 2003; Baumeister, 2016) have been the focus of previous work, although not specifically in hearing science. In line with previous work, the MoLE predicts that motivation drives engagement (the recruitment of resources) (cf. Brehm and Self, 1989; Pichora-Fuller et al., 2016; Richter et al., 2016). Motivation and engagement influence the quality of listening experiences, and experiences in turn influence motivation (but not engagement). The relation between engagement and listening experiences is the most underspecified. Experiences are rich (Wright et al., 2003; Nabi and Krcmar, 2004) and inherently subjective (but not passive; Westbrook and Braver, 2015; Bilandzic and Busselle, 2017). Whether engagement directly influences the quality of listening experiences, or whether all influences on experience depend only on motivation and comprehension success, is unknown. The time scale over which experiences evolve probably differs between experiences, and individuals may have multiple experiences concurrently. How different time scales and co-occurrences of listening experiences influence motivation and, in turn, engagement is unclear.

Cognitive processing may be assessed quantitatively (e.g., using physiological recording techniques) whereas experiences may be more directly assessed using qualitative tools and subjective reports (although indirect objective measures, reflecting subjective states, are possible). A better understanding of the relation between available cognitive resources and experiences would help determine the extent to which measures of cognition may provide proxies for listening experiences. 
527

528

529

530

531

532

533

534

535

536

537

538

539

540

541

542

543

544

545

546

547

548

549

550

551

552

553

554

555

556

557

558

559

Clinical audiologists may eventually be more interested in qualitative experiential aspects of listening rather than in resource recruitment, whereas an auditory cognitive neuroscientist may focus on motivation and resource recruitment, as the mechanisms underlying experiences. We hope the MoLE provides fruitful conceptual distinctions that enable research, fostering a new understanding of listening engagement.

\begin{abstract}
Conclusions
In the current work, we describe a model of listening engagement (MoLE) that aims to provide a conceptual foundation to understand how people engage (or not) in listening and communication. This work will help assess whether a person with hearing difficulty may be at risk of social isolation, and can be used to more completely characterize the experiences listeners may have in laboratory settings when listening to rich, engaging stimulus materials, such as stories. The MoLE posits that motivation, engagement and listening experiences are essentially interrelated, and highlights potentially fruitful areas that research may target. We hope this model will help to guide research in applied and basic hearing science and in auditory cognitive neuroscience.
\end{abstract}

\title{
Acknowledgements
}

BH was supported by a BrainsCAN Tier I postdoctoral fellowship (Canada First Research Excellence Fund; CFREF) and by the Canada Research Chair program. IJ was supported by operating funds from CIHR and NSERC.
Albrecht JE, O'Brien EJ (1993) Updating a Mental Model: Maintaining Both Local and Global Coherence. Journal of Experimental Psychology: Learning, Memory I\& Cognition 19:1061-1170.
Alhanbali S, Dawes P, Lloyd S, Munro KJ (2017) Self-Reported Listening-Related Effort and Fatigue in Hearing-Impaired Adults. Ear \& Hearing 38:e39-e48.
Alhanbali S, Dawes P, Millman RE, Munro KJ (2019) Measures of Listening Effort Are Multidimensional. Ear \& Hearing 40:1084-1097.
Althubaiti A (2016) Information bias in health research: definition, pitfalls, and adjustment methods. Journal of Multidisciplinary Healthcare 9:211-217.
Amabile TM (1993) Motivational synergy: Toward new conceptualizations of intrinsic and extrinsic motivation in the workplace. Human Resource Management Review 3:185-201.
Baguley DM (2003) Hyperacusis. Journal of the Royal Society of Medicine 96:582-585.
Bamberg M (2010) Who am I? Narration and its contribution to self and identity. Theory \& Psychology 21:1-22.
Bao J, Ohlemiller KK (2010) Age-related loss of spiral ganglion neurons. Hearing Research 264:93-97. 
Baumeister RF (2016) Toward a general theory of motivation: Problems, challenges, opportunities, and the big picture. Motivation and Emotion 40:1-10.

Benabou R, Triole J (2003) Intrinsic and extrinsic motivation. Review of Economic Studies 70:489-520. Bilandzic H, Busselle RW (2017) Beyond metaphors and traditions: Exploring the conceptual boundaries of narrative engagement. In: Narrative Absorption (Hakemulder FaK, Moniek M. and Tan, Ed S. and Bálint, Katalin and Doicaru, Miruna M., ed), pp 11-27: John Benjamins Publishing Company.

Brehm JW, Self EA (1989) The Intensity of Motivation. Annual Review of Psychology 40:109-131.

Broderick MP, Anderson AJ, Di Liberto GM, Crosse MJ, Lalor EC (2018) Electrophysiological Correlates of Semantic Dissimilarity Reflect the Comprehension of Natural, Narrative Speech. Current Biology 28:803-809.

Busselle R, Bilandzic H (2008) Fictionality and Perceived Realism in Experiencing Stories: A Model of Narrative Comprehension and Engagement. Communication Theory 18:255-280.

Busselle R, Bilandzic H (2009) Measuring Narrative Engagement. Media Psychology 12:321-347.

Caplan RD, Van Harrison R (1993) Person-Environment Fit Theory: Some History, Recent Developments, and Future Directions. Journal of Social Issues 49:253-275.

Caspary DM, Ling L, Turner JG, Hughes LF (2008) Inhibitory neurotransmission, plasticity and aging in the mammalian central auditory system. The Journal of Experimental Biology 211:1781-1791.

Chan CS, Tilburg WAPv, Igou ER, Poon CYS, Tam KYY, Wong VUT, Cheung SK (2018) Situational meaninglessness and state boredom: Cross-sectional and experience-sampling findings. Motivation and Emotion 42:555-565.

Chern A, Golub JS (2019) Age-related Hearing Loss and Dementia. Alzheimer Disease and Associated Disorders 33:285-290.

Chin A, Markey A, Bhargava S, Kassam KS, Loewenstein G (2017) Bored in the USA: Experience Sampling and Boredom in Everyday Life. Emotion 17:359-368.

Christie ST, Schrater P (2015) Cognitive cost as dynamic allocation of energetic resources. Frontiers in Neuroscience 9:Article 289.

Cohen J (2001) Defining Identification: A Theoretical Look at the Identification of Audiences With Media Characters. Mass Communication \& Society 4:245-264.

Cohen SS, Parra LC (2016) Memorable Audiovisual Narratives Synchronize Sensory and Supramodal Neural Responses. eNeuro 3:e0203.

Crosse MJ, Di Liberto GM, Bednar A, Lalor EC (2016) The Multivariate Temporal Response Function (mTRF) Toolbox: A MATLAB Toolbox for Relating Neural Signals to Continuous Stimuli. Frontiers in human neuroscience 10:604.

Cruickshanks KJ, Wiley TL, Tweed TS, Klein BEK, Klein R, Mares-Perlman JA, Nondahl DM (1998) Prevalence of Hearing Loss in Older Adults in Beaver Dam, Wisconsin. American Journal of Epidemiology 148:879-886.

Csikszentmihalyi M (1990) Flow: The Psychology of Optimal Experience. New York, USA: Harper \& Row. 
Daube C, Ince RAA, Gross J (2019) Simple Acoustic Features Can Explain Phoneme-Based Predictions of Cortical Responses to Speech. Current Biology 29:1924-1937.

Davis MH, Johnsrude IS (2007) Hearing speech sounds: top-down influences on the interface between audition and speech perception. Hearing Research 229:132-147.

Demorest ME, Erdman SA (1987) Development of the Communication Profile for the Hearing Impaired. Journal of Speech and Hearing Disorders 52:129-143.

Desjardins JL, Doherty KA (2013) Age-Related Changes in Listening Effort for Various Types of Masker Noises. Ear \& Hearing 34:261-272.

Dimitrijevic A, Smith ML, Kadis DS, Moore DR (2017) Cortical Alpha Oscillations Predict Speech Intelligibility. Frontiers in Human Neuroscience 11:Article 88.

Dmochowski JP, Bezdek MA, Abelson BP, Johnson JS, Schumacher EH, Parra LC (2014) Audience preferences are predicted by temporal reliability of neural processing. Nature Communications 29:4567.

Duchesne L, Millette I, Bhérer M, Gobeil S (2017) Auditory performance and subjective benefits in adults with congenital or prelinguistic deafness who receive cochlear implants during adulthood. Cochlear Implants International 18:143-152.

Dunlop WL, Walker LJ (2013) The life story: Its development and relation to narration and personal identity. International Journal of Behavioral Development 37:235-247.

Dweck CS (2017) From Needs to Goals and Representations: Foundations for a Unified Theory of Motivation, Personality, and Development. Psychological Review 124:689-719.

Eastwood JD, Frischen A, Fenske MJ, Smilek D (2012) The Unengaged Mind: Defining Boredom in Terms of Attention. Perspectives on Psychological Science 7:482-495.

Eckert MA, Teubner-Rhodes S, Vaden Jr. KI (2016) Is Listening in Noise Worth It? The Neurobiology of Speech Recognition in Challenging Listening Conditions. Ear \& Hearing 37:101S-110S.

Elpidorou A (2014) The bright side of boredom. Frontiers in Psychology 5:Article 1245.

Elpidorou A (2018a) The bored mind is a guiding mind: toward a regulatory theory of boredom. Phenomenology and the Cognitive Sciences 17:455-484.

Elpidorou A (2018b) The good of boredom. Philosophical Psychology 31:323-351.

Fahlman SA, Mercer-Lynn KB, Flora DB, Eastwood JD (2013) Development and validation of the multidimensional state boredom scale. Assessment 20:68-85.

Farmer R, Sundberg ND (1986) Boredom Proneness--The Development and Correlates of a New Scale. Journal of Personality Assessment 50:4-17.

Feder K, Michaud D, Ramage-Morin P, McNamee J, Beauregard Y (2015) Prevalence of hearing loss among Canadians aged 20 to 79: Audiometric results from the 2012/2013 Canadian Health Measures Survey. Health Reports 26:18-25.

Fiedler L, Wöstmann M, Herbst SK, Obleser J (2019) Late cortical tracking of ignored speech facilitates neural selectivity in acoustically challenging conditions. Neuroimage 186:33-42.

Francis AL, Oliver J (2018) Psychophysiological measurement of affective responses during speech perception. Hearing Research 369:103-119. 
Francis AL, Love J (2020) Listening effort: Are we measuring cognition or affect, or both? WIREs Cognitive Science 11:e1514.

Francis AL, MacPherson MK, Chandrasekaran B, Alvar AM (2016) Autonomic nervous system responses during perception of masked speech may reflect constructs other than subjective listening effort. Frontiers in Psychology 7:Article 263.

Fratiglioni L, Wang HX, Ericsson K, Maytan M, Winblad B (2000) Influence of social network on occurrence of dementia: a community-based longitudinal study. Lancet 355:1315-1319.

Fries P (2005) A mechanism for cognitive dynamics: neuronal communication through neuronal coherence. Trends in Cognitive Sciences 9:474-480.

Gailliot MT (2008) Unlocking the Energy Dynamics of Executive Functioning. Perspectives on Psychological Science 3:245-263.

Garcia-Leon A, del Paso GAR, Robles H, Vila J (2003) Relative effects of harassment, frustration, and task characteristics on cardiovascular reactivity. International Journal of Psychophysiology 47:159173.

Gatehouse S, Noble W (2004) The speech, spatial and qualities of hearing scale (SSQ). International Journal of Audiology 43:85-99.

Gates GA, Mills JH (2005) Presbycusis. Lancet 366:1111-1120.

Gazzaley A, Nobre AC (2010) Top-down modulation: bridging selective attention and working memory. Trends in Cognitive Sciences 16:129-135.

Gendolla GHE (2000) On the Impact of Mood on Behavior: An Integrative Theory and a Review. Review of General Psychology 4:378-408.

Gendolla GHE, Krüsken J (2001) The joint impact of mood state and task difficulty on cardiovascular and electrodermal reactivity in active coping. Psychophysiology 38:548-556.

Gendolla GHE, Richter M (2013) Opportunity cost calculations only determine justified effort--or, what happened to the resource conservation principle? Behavioral and Brain Sciences 36:686-687.

Gfeller K, Driscoll V, Schwalje A (2019) Adult Cochlear Implant Recipients' Perspectives on Experiences With Music in Everyday Life: A Multifaceted and Dynamic Phenomenon. Frontiers in Neuroscience 13:Article 1229.

Glisky EL (2007) Changes in Cognitive Function in Human Aging. In: Brain Aging: Models, Methods, and Mechanisms (Riddle DR, ed), pp 3-20. New York, USA: CRC PRess (Taylor \& Francis Group). Graesser AC, Olde B, Klettke B (2002) How does the mind construct and represent stories? In: Narrative impact: Social and cognitive foundations (Green MC, Strange JJ, Brock TC, eds), pp 229-262. Mahwah, NJ, US: Lawrence Erlbaum Associates Publishers.

Gratton MA, Vázquez AE (2003) Age-related hearing loss: current research. Current Opinion in Otolaryngology \& Head and Neck Surgery 11:367-371.

Green MC, Brock TC, Kaufman GF (2004) Understanding Media Enjoyment: The Role of Transportation Into Narrative Worlds. Communication Theory 14:311-327.

Hallberg LR, Carlsson SG (1991) A qualitative study of strategies for managing a hearing impairment. British Journal of Audiology 25:201-211. 
Heffernan E, Coulson NS, Henshaw H, Barry JG, Ferguson MA (2016) Understanding the psychosocial experiences of adults with mild-moderate hearing loss: An application of Leventhal's selfregulatory model. International Journal of Audiology 55:S3-S12.

Heine SJ, Proulx T, Vohs KD (2006) The Meaning Maintenance Model: On the Coherence of Social Motivations. Personality and Social Psychology Review 10:88-110.

Helfer KS, Merchant GR, Wasiuk PA (2017) Age-Related Changes in Objective and Subjective Speech Perception in Complex Listening Environments. Journal of Speech, Language, and Hearing Research 60:3009-3018.

Herrmann B, Maess B, Johnsrude IS (2018) Aging Affects Adaptation to Sound-Level Statistics in Human Auditory Cortex. The Journal of Neuroscience 38:1989-1999.

Hickson L, Meyer C, Lovelock K, Lampert M, Khan A (2014) Factors associated with success with hearing aids in older adults. International Journal of Audiology 53:S18-27.

Hockey GRJ (1997) Compensatory control in the regulation of human performance under stress and high workload: A cognitive-energetical framework. Biological Psychology 45:73-93.

Holube I, Haeder K, Imbery C, Weber R (2016) Subjective Listening Effort and Electrodermal Activity in Listening Situations with Reverberation and Noise. Trends in Hearing 3:20.

Hornsby BW, Naylor G, Bess FH (2016) A Taxonomy of Fatigue Concepts and Their Relation to Hearing Loss. Ear \& Hearing 37:136S-144S.

Hughes LF, Turner JG, Parrish JL, Caspary DM (2010) Processing of broadband stimuli across A1 layers in young and aged rats. Hearing Research 264:79-85.

Inzlicht M, Schmeichel BJ, Macrae CN (2014) Why self-control seems (but may not be) limited. Trends in Cognitive Sciences 18:127-133.

Johnsrude IS, Rodd JM (2016) Factors That Increase Processing Demands When Listening to Speech. In: Neurobiology of Language (Hickok G, Small SL, eds), pp 491-502: Elsevier Academic Press.

Kahneman D (1973) Attention and Effort. Englewood Cliffs, New Jersey, USA: Prentice-Hall Inc.

Kamil RJ, Genther DJ, Lin FR (2015) Factors associated with the accuracy of subjective assessments of hearing impairment. Ear \& Hearing 36:164-167.

Kanwisher N, Wojciulik E (2000) Visual attention: Insights from brain imaging. Nature Reviews Neuroscience 1:91-100.

Keitel A, Ince RAA, Gross J, Kayser C (2017) Auditory cortical delta-entrainment interacts with oscillatory power in multiple fronto-parietal networks. NeuroImage 147:32-42.

Ki JJ, Kelly SP, Parra LC (2016) Attention Strongly Modulates Reliability of Neural Responses to Naturalistic Narrative Stimuli. The Journal of Neuroscience 36:3092-3101.

Kilman L, Zekveld A, Hällgren M, Rönnberg J (2015) Native and Non-native Speech Perception by Hearing-Impaired Listeners in Noise- and Speech Maskers. Trends in Hearing 19:1-12.

Krueger M, Schulte M, Brand T, Holube I (2017) Development of an adaptive scaling method for subjective listening effort. The Journal of the Acoustical Society of America 141:4680-4693.

Kuijpers MM, Hakemulder F, Tan ES, Doicaru MM (2014) Exploring absorbing reading experiences. Scientific Study of Literature 4:89-122. 
716

Kujawa SG, Liberman MC (2009) Adding Insult to Injury: Cochlear Nerve Degeneration after "Temporary" Noise-Induced Hearing Loss. The Journal of Neuroscience 29:14077-14085.

Lalor EC, Foxe JJ (2010) Neural responses to uninterrupted natural speech can be extracted with precise temporal resolution. European Journal of Neuroscience 31:189-193.

Larsby B, Hällgren M, Lyxell B, Arlinger S (2005) Cognitive performance and perceived effort in speech processing tasks: Effects of different noise backgrounds in normal-hearing and hearing-impaired subjects. International Journal of Audiology 44:131-143.

Lau MK, Hicks C, Kroll T, Zupancic S (2019) Effect of Auditory Task Type on Physiological and Subjective Measures of Listening Effort in Individuals With Normal Hearing. Journal of Speech, Language, and Hearing Research 62:1549-1560.

Lavie N (2005) Distracted and confused?: Selective attention under load. Trends in Cognitive Sciences 9:75-82.

Lavie N, Beck DM, Konstantinou N (2014) Blinded by the load: attention, awareness and the role of perceptual load. Philosophical Transactions of the Royal Society B: Biological Sciences 369:20130205.

Lemke U, Besser J (2016) Cognitive Load and Listening Effort: Concepts and Age-Related Considerations. Ear \& Hearing 37:77S-84S.

Liberman MC, Kujawa SG (2017) Cochlear synaptopathy in acquired sensorineural hearing loss: Manifestations and mechanisms. Hearing Research 349:138-147.

Lin FR, Albert M (2014) Hearing loss and dementia - who is listening? Aging \& Mental Health 18:671673.

Lindenberger U (2014) Human cognitive aging: Corriger la fortune? Science 346:572-578.

Mackersie CL, Cones H (2011) Subjective and psychophysiological indices of listening effort in a competing-talker task. Journal of the American Academy of Audiology 22:113-122.

Madsen SM, Moore BCJ (2014) Music and hearing aids. Trends in Hearing 18:2331216514558271.

Mar RA, Oatley K (2008) The Function of Fiction is the Abstraction and Simulation of Social Experience. Perspectives on Psychological Science 3:173-192.

Marinelli A (2017) A Qualitative Examination of the Listening EffortExperience of Adults with Hearing Loss. In: Speech, Language, and Hearing Sciences: University of Connecticut.

Matthen M (2016) Effort and Displeasure in People Who Are Hard of Hearing. Ear \& Hearing 37 Suppl $1: 28 \mathrm{~S}-34 \mathrm{~S}$.

Mattys SL, Brooks J, Cooke M (2009) Recognizing speech under a processing load: Dissociating energetic from informational factors. Cognitive Psychology 59:203-243.

Mattys SL, Davis MH, Bradlow AR, Scott SK (2012) Speech recognition in adverse conditions: A review. Language and Cognitive Processes 27:953-978.

McGarrigle R, Munro KJ, Dawes P, Stewart AJ, Moore DR, Barry JG, Amitay S (2014) Listening effort and fatigue: What exactly are we measuring? A British Society of Audiology Cognition in Hearing Special Interest Group 'white paper’. International Journal of Audiology 53:433-440.

Mick P, Kawachi I, Lin FR (2014) The association between hearing loss and social isolation in older adults. Otolaryngology - Head and Neck Surgery 150:378-384. 
Miles K, McMahon C, Boisvert I, Ibrahim R, de Lissa P, Graham P, Lyxell B (2017) Objective Assessment of Listening Effort: Coregistration of Pupillometry and EEG. Trends in Hearing 21:113.

Miller EK, Buschman TJ (2015) Working Memory Capacity: Limits on the Bandwidth of Cognition. Daedalus 144:112-122.

Mitchell TR (1982) Motivation: New Directions for Theory, Research, and Practice. The Academy of Management Review 7:80-88.

Moore BCJ (2007) Cochlear Hearing Loss: Physiological, Psychological and Technical Issues. West Sussex, Engand: John Wiley \& Sons, Ltd.

Nabi RL, Krcmar M (2004) Conceptualizing Media Enjoyment as Attitude: Implications for Mass Media Effects Research. Communication Theory 14:288-310.

Navon D, Gopher D (1979) On the economy of processing systems. Psychological Review 89:214-255. Nicholson NR (2009) A Review of Social Isolation: An Important but Underassessed Condition in Older Adults. The Journal of Primary Prevention 33:137-152.

Nilsson M, Soli SD, Sullivan JA (1994) Development of the Hearing In Noise Test for the measurement of speech reception thresholds in quiet and in noise. The Journal of the Acoustical Society of America 95:1085-1099.

Nisbett RE, Wilson TD (1977) Telling more than we can know: Verbal reports on mental processes. Psychological Review 84:231-259.

Norman DA, Bobrow DG (1975) On Data-limited and Resource-limited Processes. Cognitive Psychology 7:44-64.

Oatley K (1999) Meetings of minds: Dialogue, sympathy, and identification, in reading fiction. Poetics 26:439-454.

Park DC, Reuter-Lorenz P (2009) The Adaptive Brain: Aging and Neurocognitive Scaffolding. Annual Review of Psychology 60:173-196.

Peelle JE (2018) Listening Effort: How the Cognitive Consequences of Acoustic Challenge Are Reflected in Brain and Behavior. Ear \& Hearing 39:204-214.

Phillips NA (2016) The Implications of Cognitive Aging for Listening and the Framework for Understanding Effortful Listening (FUEL). Ear \& Hearing 37:44S-51S.

Pichora-Fuller MK (2003) Processing speed and timing in aging adults: psychoacoustics, speech perception, and comprehension. International Journal of Audiology 42:S59-S67.

Pichora-Fuller MK (2016) How Social Psychological Factors May Modulate Auditory and Cognitive Functioning During Listening. Ear \& Hearing 37 Suppl 1:92S-100S.

Pichora-Fuller MK, Levitt H (2012) Speech Comprehension Training and Auditory and Cognitive Processing in Older Adults. American Journal of Audiology 21:351-357.

Pichora-Fuller MK, Kramer SE, Eckert MA, Edwards B, Hornsby BWY, Humes LE, Lemke U, Lunner T, Matthen M, Mackersie CL, Naylor G, Phillips NA, Richter M, Rudner M, Sommers MS, Tremblay KL, Wingfield A (2016) Hearing Impairment and Cognitive Energy: The Framework for Understanding Effortful Listening (FUEL). Ear \& Hearing 37 Suppl 1:5S-27S. 
Picou EM, Ricketts TA (2014) Increasing motivation changes subjective reports of listening effort and choice of coping strategy. International Journal of Audiology 53:418-426.

Plack CJ (2014) The sense of hearing. New York, USA: Psychology Press.

Poldrack RA, Yarkoni T (2016) From Brain Maps to Cognitive Ontologies: Informatics and the Search for Mental Structure Annual Review of Psychology 67:587-612.

Presacco A, Simon JZ, Anderson S (2016) Evidence of degraded representation of speech in noise, in the aging midbrain and cortex. Journal of Neurophysiology 116:2346-2355.

Puvvada KC, Simon JZ (2017) Cortical Representations of Speech in a Multi-talker Auditory Scene. The Journal of Neuroscience 37:9189-9196.

Reitan RM, Wolfson D (2000) Conation: A Neglected Aspect of Neuropsychological Functioning. Archives of Clinical Neuropsychology 15:443-453.

Reitan RM, Wolfson D (2004) The differential effect of conation on intelligence test scores among braindamaged and control subjects. Archives of Clinical Neuropsychology 19:29-35.

Richter M (2013) A Closer Look Into the Multi-Layer Structure of Motivational Intensity Theory. Social and Personality Psychology Compass 7:1-12.

Richter M (2016) The Moderating Effect of Success Importance on the Relationship Between Listening Demand and Listening Effort. Ear \& Hearing 37:111-117.

Richter M, Gendolla GHE, Krüsken J (2006) Context-dependent mood effects on mental effort mobilization: A view from the Mood-Behavior-Model. In: Psychology of Moods: New Research (Clark AV, ed), pp 57-79. New York, USA: Nova Science Publishers.

Richter M, Gendolla GHE, Wright RA (2016) Three Decades of Research on Motivational Intensity Theory: What We Have Learned About Effort and What We Still Don't Know. In: Advances in Motivation Science (Elliot AJ, ed), pp 149-186. Cambridge, MA, USA: Academic Press.

Ryan M-L (2007) Toward a definition of narrative. In: The Cambridge Companion to Narrative (Herman D, ed), pp 22-35. Cambridge: Cambridge University Press.

Ryan RM, Deci EL (2000) Intrinsic and Extrinsic Motivations: Classic Definitions and New Directions. Contemporary Educational Psychology 25:54-67.

Salvi R, Sun W, Ding D, Chen G-D, Lobarinas E, Wang J, Radziwon K, Auerbach BD (2017) Inner Hair Cell Loss Disrupts Hearing and Cochlear Function Leading to Sensory Deprivation and Enhanced Central Auditory Gain. Frontiers in Neuroscience 10:Article 621.

Sanders AF (1997) A summary of resource theories from a behavioral perspective. Biological Psychology 45.

Scheibe KE, Barrett FJ (2017) The Role of Imagination in Narrative Construction. In: The Storied Nature of Human Life : The Life and Work of Theodore R. Sarbin, pp 147-164. Cham, Switzerland: Springer International Publishing AG.

Schneider EN, Bernarding C, Francis AL, Hornsby BWY, Strauss DJ (2019) A Quantitative Model of Listening Related Fatigue. In: 9th International IEEE EMBS Conference on Neural Engineering. San Francisco, CA, USA.

Scott SK, Johnsrude IS (2003) The neuroanatomical and functional organization of speech perception. Trends in Neurosciences 26:100-107. 
Shenhav A, Musslick S, Lieder F, Kool W, Griffiths TL, Cohen JD, Botvinick MM (2017) Toward a Rational and Mechanistic Account of Mental Effort. Annual Review of Neuroscience 40:99-124. Shinn-Cunningham BG (2008) Object-based auditory and visual attention. Trends in Cognitive Sciences 12:182-186.

Shukla A, Harper M, Pedersen E, Goman A, Suen JJ, Price C, Applebaum J, Hoyer M, Lin FR, Reed NS (in press) Hearing Loss, Loneliness, and Social Isolation: A Systematic Review. Otolaryngology - Head and Neck Surgery.

Silbert LJ, Honey CJ, Simony E, Poeppel D, Hasson U (2014) Coupled neural systems underlie the production and comprehension of naturalistic narrative speech. Proceedings of the National Academy of Sciences 111:E4687-E4696.

Solheim J, Kværner KJ, Sandvik L, Falkenberg E-S (2012) Factors affecting older adults' hearing-aid use. Scandinavian Journal of Disability Research 14:300-312.

Strand JF, Brown VA, Merchant MB, Brown HE, Smith J (2018) Measuring Listening Effort: Convergent Validity, Sensitivity, and Links With Cognitive and Personality Measures. Journal of Speech Language and Hearing Research 61:1463-1486.

Strauß A, Wöstmann M, Obleser J (2014) Cortical alpha oscillations as a tool for auditory selective inhibition. Frontiers in Human Neuroscience 8:Article 350.

Strauss DJ, Francis AL (2017) Toward a taxonomic model of attention in effortful listening. Cognitive, Affective \& Behavioral Neuroscience 17:809-825.

Summerfield C, Egner T (2009) Expectation (and attention) in visual cognition. Trends in Cognitive Sciences 13:403-409.

Thackray RI, Bailey JP, Touchstone RM (1977) Physiological, Subjective, and Performance Correlates of Reported Boredom and Monotony While Performing a Simulated Radar Control Task. In: Vigilance (Mackie RR, ed), pp 203-215. Boston, MA, USA: NATO Conference Series.

Tilburg WAPv, Igou ER (2012) On boredom: Lack of challenge and meaning as distinct boredom experiences. Motivation and Emotion 36:181-194.

Tyler RS, Pienkowski M, Roncancio ER, Jun HJ, Brozoski T, Dauman N, Coelho CB, Andersson G, Keiner AJ, Cacace AT, Martin N, Moore BCJ (2014) A Review of Hyperacusis and Future Directions: Part I. Definitions and Manifestations. American Journal of Audiology 23:402-419.

van der Wel P, van Steenbergen H (2018) Pupil dilation as an index of effort in cognitive control tasks: A review. Psychonomic Bulletin \& Review 25:2005-2015.

Weinstein BE, Ventry IM (1982) Hearing impairment and social isolation in the elderly. Journal of Speech and Hearing Research 25:593-599.

Wendt D, Dau T, Hjortkjær J (2016) Impact of Background Noise and Sentence Complexity on Processing Demands during Sentence Comprehension. Frontiers in Psychology 7:Article 345. Westbrook A, Braver TS (2015) Cognitive effort: A neuroeconomic approach. Cognitive, Affective \& Behavioral Neuroscience 15:395-415.

Westgate EC, Wilson TD (2018) Boring Thoughts and Bored Minds: The MAC Model of Boredom and Cognitive Engagement. Psychological Review 125:689-713. WHO (2002) Active Ageing: A Policy Framework. 
Wickens CD (2002) Multiple resources and performance prediction. Theoretical issues in ergonomics science 3:159-177.

Wickens CD (2008) Multiple Resources and Mental Workload. Human Factors 50:449-455.

Wingfield A (2016) Evolution of Models of Working Memory and Cognitive Resources. Ear \& Hearing $37: 35 \mathrm{~S}-43 \mathrm{~S}$.

Winn MB, Wendt D, Koelewijn T, Kuchinsky SE (2018) Best Practices and Advice for Using Pupillometry to Measure Listening Effort: An Introduction for Those Who Want to Get Started. Trends in Hearing 22:2331216518800869.

Wöstmann M, Herrmann B, Wilsch A, Obleser J (2015) Neural Alpha Dynamics in Younger and Older Listeners Reflect Acoustic Challenges and Predictive Benefits. The Journal of Neuroscience 35:1458-1467.

Wright PC, McCarthy J, Meekison L (2003) Making sense of experience. In: Funology: HumanComputer Interaction Series (Blythe MA, Monk AF, Overbeeke K, Wright PC, eds), pp 43-53. Netherlands: Kluwer Academic Publishers.

Wright RA (2014) Presidential address 2013: Fatigue influence on effort - considering implications for self-regulatory restraint. Motivation and Emotion 38:183-195.

Zanto TP, Gazzaley A (2017) Cognitive Control and the Ageing Brain. In: The Wiley Handbook of Cognitive Control (Egner T, ed), pp 476-490: John Wiley \& Sons.

Zekveld AA, Kramer SE, Festen JM (2010) Pupil response as an indication of effortful listening: the influence of sentence intelligibility. Ear \& Hearing.

Zekveld AA, Koelewijn T, Kramer SE (2018) The Pupil Dilation Response to Auditory Stimuli: Current State of Knowledge. Trends in Hearing 22:1-25.

\footnotetext{
Appendix

A MATLAB implementation of the MoLE is available for download at https://osf.io/eksfq/. The MoLE assumes that a listener is equipped with $n$ number of executive and other cognitive resources. We represent the limit for each resource as the vector $\boldsymbol{l}=\left\{l_{1}, \ldots, l_{n}\right\}$. The resource amounts required to meet the demands of a given listening situation is represented as the vector $\boldsymbol{r}=\left\{r_{1}, \ldots, r_{n}\right\}$. The relative resource amounts required is calculated as:

$$
r a=1-\left(\frac{r}{l}\right)
$$

, where the division is calculated element-wise, that is $\boldsymbol{r a}=\left\{r a_{1}, \ldots, r a_{n}\right\}$. The resource amount available $(a v)$ to a listener is calculated as the minimum of the relative resource amounts:

$$
a v=\min r \boldsymbol{a}
$$


The amount of resources available ( $a v)$ influences whether a listener engages or disengages. An engagement factor $e$ ranging from 0 to 1 is calculated as follows:

$$
e=\mathrm{E}(a v, \varepsilon, \tau 1, \tau 2)
$$

, where $\mathrm{E}$ is the engagement function according to the following equation:

$$
\mathrm{E}(a v, \varepsilon, \tau 1, \tau 2)=\left\{\begin{array}{c}
0, \quad a v<\tau 1-\varepsilon \\
\sin \left(\frac{\pi(a v+\tau 1)}{2 \varepsilon}+\frac{\pi}{2}\right), \quad \tau 1-\varepsilon \leq a v \leq \tau 1 \\
1, \quad \tau 1<a v<\tau 2 \\
0.5 \cos \left(\frac{\pi(a v+\tau 2)}{N-\tau 2}\right)+0.5, \quad \tau 2 \leq a v \leq 1 \\
0, \quad 1<a v
\end{array}\right.
$$

$\mathrm{E}$ is a window function that consists of sinusoid-based ramps and falls and a plateau. $\tau 1$ and $\tau 2$ reflect the points on the $\mathrm{x}$-axis at which the ramp peaks and the fall starts, respectively. The parameter $\varepsilon$ determines the slope of the fall. The values used for $\tau 1, \tau 2$, and $\varepsilon$ in Figure 1 were $0,0.8$, and 0.05, respectively. Changes to the parameters $\tau 1, \tau 2$, and $\varepsilon$ will alter the engagement function. For example, to implement low motivation in Figure 2, the values of $\tau 1, \tau 2$, and $\varepsilon$ were $0.2,0.8,0.05$, respectively.

The recruited resource amounts $\boldsymbol{c}=\left\{c_{1}, \ldots, c_{n}\right\}$ are calculated as the required resource amounts $\boldsymbol{r}$ weighted by the engagement factor $e$ :

$$
c=r e
$$

In most cases the elements in $c$ are either zero (fully disengaged) or reflect the required resource amounts $\boldsymbol{r}$ (fully engaged). The elements in $\boldsymbol{c}$ can theoretically take on values between full engagement and full disengagement; that is, an intermediate proportion of the required resource amounts is recruited (this is related to the ramp/fall parts of the engagement function E), but this may be the exception rather than the norm.

In order to implement interactions between resources (Figure 3), $\boldsymbol{l}$ and $\boldsymbol{r}$ need to be replaced by $\boldsymbol{l}+\boldsymbol{l} \boldsymbol{L}$ and $\boldsymbol{r}+\boldsymbol{r} \boldsymbol{R}$, respectively, where $\boldsymbol{L}$ and $\boldsymbol{R}$ are square matrices whose non-zero diagonal elements mark a proportional change in resource limits $(\boldsymbol{L})$ and required resource amounts $(\boldsymbol{R})$, respectively. The following matrices were used to implement the compensatory interaction between resources, as displayed in Figure 3:

$$
\boldsymbol{L}=\left[\begin{array}{cc}
0.1 & 0 \\
0 & 0
\end{array}\right] \text { and } \boldsymbol{R}=\left[\begin{array}{cc}
0 & 0 \\
0 & 0.5
\end{array}\right]
$$

Here, the limit of resource 1 (Figure 3) increases by 10\%, whereas the required resource amounts of resource 2 (Figure 3 ) increases by $50 \%$. 